\title{
Opportunities, Time, and Mechanisms in Entrepreneurship: On The Practical Irrelevance of Propensities
}

\author{
Henrik Berglund* \\ Chalmers University of Technology, \\ Department of Technology Management and Economics \\ and \\ University of Oslo, \\ Centre for Entrepreneurship \\ henber@chalmers.se \\ Steffen Korsgaard \\ Aarhus University, \\ Department of Management \\ and \\ University of Oslo, \\ Centre for Entrepreneurship \\ * Corresponding author
}

Academy of Management Review, forthcoming 
Since the notion of opportunities is still a central construct in entrepreneurship studies, we applaud Ramoglou and Tsang's (2016, hereafter R\&T) recent effort to engage its philosophical underpinnings and related theoretical and practical value. R\&T ground their arguments in Roy Bhaskar's critical realism where a distinction is made between three ontological domains: the real, the actual, and the empirical. In this stratified ontology, it is only the entities and generative mechanisms operating in the domain of the real that have propensities and causal agency. Events in the domain of the actual (i.e. events that happen) or the empirical (i.e. events that we experience) are merely actualized manifestations of the empirically unobservable entities and generative mechanisms that continuously operate under the surface. Based on this meta-theory, R\&T argue that opportunities exist as independent entities on the level of the real in terms of "the propensity of market demand to be actualized into profits" (R\&T: 411). These opportunities-as-market-demand-propensities are then actualized, or not, as profitable ventures on the level of the actual. To illustrate, R\&T use the analogy of a seed whose innate propensity to become a flower will be actualized should circumstances be right, but will remain unactualized should they not.

R\&T paint a very deterministic picture that downplays the many empirical and conceptual accounts of entrepreneurship as an open-ended and collective process that unfolds in real time and transforms individuals, ventures, and environments in largely unpredictable ways (Sarasvathy and Dew, 2005a; Gartner, Bird, \& Starr, 1992; Garud et al. 2016; McMullen \& Dimov, 2013; Korsgaard, Berglund, Thrane, \& Blenker, 2016). In fact, the analogy of a seed actualizing into a flower treats time as something that 
influences only whether and how fast a seed becomes a flower; regardless of time passed the seed will never be anything but a flower. Yet time in social systems is often said to introduce true uncertainty, or at the very least effective unpredictability, partly by dint of transformative human action and interaction (Knight 1921; Lane and Maxfield, 2005). Stated in the terminology of critical realism, this means that any propensity existing at the deeper ontological level, can be manifested in a multitude of different ways at the level of the actual. However, since these manifestations will take place in the future, the connection between the opportunity-as-market-demand-propensity (on the level of the real) and the actualization of a profitable venture (on the level of the actual) is very difficult to establish since whatever profitable venture is actualized will in fact have depended on an unknown set of complexly interacting empirically unobservable generative mechanisms. We would argue that entrepreneurship concerns quintessentially open systems and that R\&T present a needlessly and problematically deterministic view of the process. Indeed, even Bhaskar and other critical realists clearly acknowledge the challenges of establishing cause and effect in open system: "it is characteristic of open systems that two or more mechanisms, perhaps of radically different kinds ['natural', 'social', 'human', 'physical', 'chemical', 'aerodynamical', 'biological', 'economic', etc], combine to produce effects; so that because we do not know ex ante which mechanisms will actually be at work (and perhaps have no knowledge of their mode of articulation) events are not deductively predictable" (Bhaskar 2008: 109).

This arguably holds true both ex ante and ex post in entrepreneurship. To conclude from an actual event that a specific set of such mechanism existed and interacted to cause it, is necessarily speculative due to the tremendous complexity and 
hence causal ambiguity involved in entrepreneurial processes. In the words of Lewis, the causal histories of empirical events (such as the development of a new and profitable venture) are typically so overwhelming that the only question is whether explanations need to be "infinite or merely enormous" (Lewis, 1986: 214). In addition, entrepreneurial processes often end up transforming the social systems in which entities and mechanisms are supposedly embedded, thus undermining their stability. R\&T appear to acknowledge these difficulties in general since empirical events are said to be the result of "variously and complexly interacting causally powerful structures and generative mechanisms" (R\&T: 412). However, they surprisingly maintain that in the case of entrepreneurship, opportunities-as-market-demand-propensities can be known to exist, ex post as well as ex ante, in theoretically and practically meaningful ways.

Besides the unsatisfactory treatment of time and uncertainty, R\&T's use of critical realism to save the objectivity of entrepreneurial opportunities begs the more fundamental questions of why it should be saved, and whether critical realism is suitable for the task. Critical realism is often held forth as a conceptual underlaborer or midwife (Bhaskar 2008) of applied work that provides value through its explicit (and according to its proponents true) meta-theoretical underpinnings. But how do critical realists motivate their bold claims about independent and ontologically real existence of causal mechanisms and entities operating on various levels (and by implication of opportunitiesas-market-demand-propensities)? Since such mechanisms and entities are by definition unobservable, critical realists tend to rely on a causal existence criterion; a view explicitly echoed by R\&T when they state that "unactualized powers are never directly observable but no-less-real, and (under certain conditions) can be evidenced through their effects" 
(R\&T: 412 emphasis added). However, such a causal criterion of existence is problematic when 1) mechanisms and other entities such as opportunities can have causal powers and propensities without exercising them, and 2) their empirical realization is obscured by complex interactions with other mechanisms and entities (Hedström, 2005). R\&T agree that these conditions hold true when they write that:

"propensities may remain unactualized because powers may not be triggered, and when triggered they need not be evident either because countervailing factors may constrain their empirical realization, or because additional enabling factors might be absent. In such occasions unobservable tendencies are said to operate transfactually. “(R\&T: 412).

The claim to existence and causal effects of mechanisms in general, and of opportunitiesas-market-demand-propensities in particular, is thus grounded in "empirically unobservable effects of an empirically unobservable entity" (Hedström 2005:72). For both meta-theoretical and practical relevance reasons, this is clearly not satisfactory. However, this does not mean that all mechanism-based explanations emphasizing causality are unsuitable for entrepreneurship. On the contrary, the past decades have seen the growth of a rich literature on social mechanisms and mechanism-based explanations (e.g. Schelling, 1978; Elster, 1989; Hedström and Swedberg 1998; Hedström and Ylikoski 2010) that share with critical realists an aversion towards naïve positivism and constant-conjunction notions of causality, and that also seeks to explain events and outcomes in terms of causal mechanisms. But, where critical realists rely on a complex 
meta-theoretical system to produce causal explanations, the social mechanisms tradition employs a more mundane and methodologically individualist form of mechanism-based explanation, emphasizing realistic descriptions of how socially embedded actors in interaction with one and other can bring about social phenomena (Hedström and Swedberg 1998). A paradigmatic example in this tradition is Merton's self-fulfilling prophecy, which was originally illustrated with a bank run (Merton 1968) where the mechanism works as follows. A rumor of insolvency gets started, leading some depositors to withdraw their savings. This begins to hurt the bank, but more importantly signals to other depositors that the bank may be in trouble. As a result, more people withdraw their savings, triggering more withdrawals and so on, until the bank in fact becomes insolvent.

There are important differences between these two types of mechanism-based explanations, one of which concerns the question of how to reduce the enormously complex causal histories mentioned above (Lewis 1986). Where critical realists will postulate the existence of unobservable entities (such as opportunities-as-market-demandpropensities) and explain their empirical actualization (such as the development of a profitable new venture) as caused by a complex set of also unobservable and “transfactually" active mechanisms, social mechanism explanations explicitly favor empirically tractable accounts of how socially embedded action and interaction produce social outcomes. A social mechanism take on opportunities would therefore eschew an abstract, agent-independent, and causal notion of opportunity. Instead, explanations would likely focus on questions such as: how can actors with heterogeneous "opportunity visions" interact to produce a new organization based on a "shared opportunity vision". 
While not explicitly proposing a social mechanism, consider the theory of effectuation (Sarasvathy 2009) as an example of what such an explanation might look like.

Effectuation describes how an entrepreneur, based on a given set of means (including a network of relations) and personal goals, interacts with other individuals. These interactions lead to some individuals joining the entrepreneurial effort, thus expanding the set of means but also constraining the goals in the sense that they are now jointly negotiated. Based on the new set of means (including an expanded network) and the new goals, what is now an entrepreneurial team interacts with more individuals, some of whom also come onboard thus further expanding the means and constraining the goals, and so on, until a shared "opportunity vision" stabilizes (cf. Sarasvathy and Dew 2005a). While we are clearly critical of R\&T's critical realist brand of causal analysis, we see definite potential and also some interesting challenges for entrepreneurship researchers who adopt the social mechanism brand of causal analysis. In general, we argue that the assumptions on which social mechanisms are based should be empirically tractable, realistic, and fit the phenomenon and explanatory purpose at hand (Hedström and Ylykoski 2010: 60). Here, the study of entrepreneurship might pose special challenges. Just as mechanisms developed by sociologists often require more nuanced psychological and social assumptions than is the case in more strongly methodologically individualistic fields, such as economics, (Hedström and Swedberg 1998), so should entrepreneurship scholars develop mechanisms grounded in assumptions that fit the actions and phenomena they seek to explain. For instance, to the extent that entrepreneurial processes are transformative-not only in the traditional sense of producing collective outcomes, but also in the sense of transforming the identities and 
goals of the actors involved (e.g. McMullen and Dimov, 2013; Garud et al. 2016; cf. March 1978) - behavioral assumptions should probably include aspects of docility and the capacity to influence and be influenced by others (cf. Sarasvathy and Dew 2005b). Entrepreneurship scholars might therefore be wise to consider Gross' (2009) suggestion to ground social mechanisms in conceptions of human action that explicitly go beyond utilitarian rational choice accounts (cf. Sarasvathy and Berglund, 2010; and Berglund, 2015).

We will not go deeper into the opportunities and challenges we see in social mechanism-based explanations for entrepreneurship. Instead, we conclude by suggesting that entrepreneurship scholars pay attention to R\&T's critique of naïve positivism and their emphasis on mechanisms and causal explanations. However, we see no value in using critical realism as a meta-theoretical crutch to save the realness and independence of entrepreneurial opportunities, and more generally to conceive of entrepreneurial processes and outcomes as caused by complexly interacting and empirically unobservable entities and mechanisms. Instead, we urge scholars to consider explanations that focus on empirically tractable social mechanisms that connect social action and interaction with relevant outcomes in ways that take into account the open-endedness, uncertainty, and transformative character of entrepreneurship. 


\section{References}

Berglund, H. (2015). Between Cognition and Discourse: Phenomenology and the Study of Entrepreneurship. International Journal of Entrepreneurial Behaviour \& Research. Special Issue: Embracing Qualitative Research Philosophies and Methods. 21(3): 472-288.

Bhaskar, R. (2008). A Realist Theory of Science, 4th edn. London: Routledge.

Elster, J. (1989). Nuts and bolts for the social sciences. Cambridge: Cambridge University Press.

Garud, R., Gehman, J. \& Kumaraswamy, A. \& Tuertscher, P. (2016). From the Process of Innovation to Innovation as Process. In A. Langley \& H. Tsoukas (eds), The Sage Handbook of Process Organization Studies. Forthcoming.

Gartner, W. B., Bird, B. J., \& Starr, J. A. (1992). Acting As If: Differentiating Entrepreneurial From Organizational Behavior. Entrepreneurship: Theory \& Practice, 16(3), 13-31.

Gross, N. (2009). A pragmatist theory of social mechanisms. American Sociological Review, 74(3), 358-379.

Hedström, P. (2005). Dissecting the social: On the principles of analytical sociology. Cambridge University Press.

Hedström, P. and Swedberg, R. (1998). Social mechanisms: An analytical approach to social theory. Cambridge: Cambridge University Press.

Hedström, P. and Ylikoski, P. (2010). Causal mechanisms in the social sciences. Annual Review of Sociology, 36: 49-67.

Knight, F. (1921). Risk, Uncertainty and Profit. Boston and New York: Houghton Mifflin.

Korsgaard, S., Berglund, H., Thrane, C., \& Blenker, P. (2016). A Tale of Two Kirzners: Time, Uncertainty and the 'Nature' of Opportunities. Entrepreneurship: Theory \& Practice. 40(4): 867-889.

Lane, D. A., \& Maxfield, R. R. (2005). Ontological uncertainty and innovation. Journal of evolutionary economics, 15(1), 3-50.

Lewis, D. (1986). Causal explanation. In his Philosophical Papers, Vol. 2: 214-240.

March, J. (1978). Bounded rationality, ambiguity, and the engineering of choice. The Bell Journal of Economics, 587-608.

McMullen, J. S., \& Dimov, D. (2013). Time and the Entrepreneurial Journey: The Problems and Promise of Studying Entrepreneurship as a Process. Journal of Management Studies, 50(8), 1481-1512. doi:10.1111/joms.12049

Merton, R. K. (1968). Social theory and social structure. Simon and Schuster. 
Ramoglou, S., \& Tsang, E. (2016). A Realist Perspective of Entrepreneurship: Opportunities as Propensities. Academy of Management Review. 41(3): 410-434.

Sarasvathy, S. D. (2009). Effectuation: Elements of entrepreneurial expertise. Edward Elgar Publishing.

Sarasvathy, S and Berglund, H. (2010). On the Relevance of Decision Making in Entrepreneurial Decision Making. In Landström, H. and Lohrke,L. (Eds.). The Historical Foundations of Entrepreneurship Research, pp. 75-93. Edward Elgar, Aldershott, UK.

Sarasvathy, S. D., \& Dew, N. (2005a). New market creation through transformation. Journal of Evolutionary Economics, 15(5), 533-565.

Sarasvathy, S. D., \& Dew, N. (2005). Entrepreneurial logics for a technology of foolishness. Scandinavian Journal of Management, 21(4), 385-406.

Schelling, T. (1978). Micromotives and Macrobehavior. New York: Norton. 